\title{
INSERÇÃO DE GRADUADOS EM FONOAUDIOLOGIA DE UMA UNIVERSIDADE PÚBLICA EM PROGRAMAS DE PÓS-GRADUAÇÃO
}

\section{Insertion of speech and language therapy undergraduate students, from a public university, in communication disorder graduate programs}

\author{
Viviane Cristina de Castro Marino (1), Sandra Regina Gimeniz-Paschoal (2), Andréa Carla Paura (3), \\ Heraldo Lorena Guida ${ }^{(4)}$, Célia Maria Giacheti ${ }^{(5)}$
}

\begin{abstract}
RESUMO
Objetivo: caracterizar a inserção de egressos do Curso de Fonoaudiologia da Universidade Estadual Paulista (UNESP) - Marília, em Programas de Pós-Graduação (PPG) Stricto Sensu brasileiros. Método: foram utilizadas listas de graduados e Curriculum Vitae do egresso e do orientador. Resultados: dos 537 formados, 16,57\% cursaram/estavam cursando PPG e destes, 98,88\% em mestrado e $37,08 \%$ também em doutorado. Na grande área de conhecimento, $50 \%$ dos egressos de mestrado vincularam-se predominantemente a programas em Ciências da Saúde, 31,80\% em Ciências Humanas e 13,64\% em Linguística, Letras e Artes. No doutorado, 33, 33\% em Ciências Humanas, 30,30\% em Ciências da Saúde e em Linguística, Letras e Artes. Quanto à área de conhecimento, predominou a vinculação, no mestrado, de 30,68\% em Fonoaudiologia, 28,41\% em Educação, 13,64\% em Linguística e 9,09\% em Medicina I; e, no doutorado, de 33,33\% em Educação, 30,30\% em Linguística e 9,09\% em Fonoaudiologia; 55,68\% dissertações e 51,52\% teses focalizaram a linguagem. A UNESP predominou com $39,77 \%$ no mestrado e $48,48 \%$ no doutorado. Predominou a vinculação a Programas com conceito 4 para $52,27 \%$ dos egressos do mestrado e $45,45 \%$ do doutorado. Quando constou a informação (55,68\%), todos receberam fomento. O Teste de Razão de Verossimilhança não indicou diferenças significativas dos percentuais obtidos entre o mestrado e o doutorado. Conclusão: os resultados superaram os apresentados para o mesmo Estado, mostraram a característica interdisciplinar da Ciência Fonoaudiológica e o predomínio de temática em linguagem.
\end{abstract}

DESCRITORES: Fonoaudiologia; Educação; Formação de Recursos Humanos

(1) Fonoaudióloga; Professor assistente doutor da Faculdade de Filosofia e Ciências - da Universidade Estadual Paulista UNESP, Marília, SP, Brasil; Doutor em Ciências - Distúrbios da Comunicação Humana pelo Hospital de Reabilitação de Anomalias Craniofaciais - HRAC/USP.

(2) Psicóloga; Professor assistente doutor daFaculdade de Filosofia e Ciências da Universidade Estadual Paulista UNESP, Marília, SP, Brasil; Doutor em Psicologia pela Universidade de São Paulo - USP.

(3) Fonoaudióloga; Membro do Grupo de Pesquisa Avaliação da Linguagem e da Fala da Faculdade de Filosofia e Ciências da Universidade Estadual Paulista - UNESP

(4) Fonoaudiólogo; Professor assistente doutor da Faculdade de Filosofia e Ciências da Universidade Estadual Paulista UNESP, Marília, SP, Brasil; Doutor em Ciências - Anatomia pela Universidade Estadual Paulista - UNESP.

(5) Fonoaudióloga; Professor adjunto da Faculdade de Filosofia e Ciências da Universidade Estadual Paulista - UNESP, Marília, SP, Brasil, Livre Docente em Diagnóstico Fonoaudiológico pela Universidade Estadual Paulista - UNESP.

Conflito de interesses: inexistente

\section{INTRODUÇÃO}

A Ciência Fonoaudiológica tem como objeto de estudo a comunicação humana - no que se refere ao seu desenvolvimento, aperfeiçoamento, distúrbios e diferenças - em relação a aspectos envolvidos na função auditiva periférica e central, na função vestibular, na função cognitiva, na linguagem oral e escrita, na fala, na fluência, na voz e nas funções orofaciais ${ }^{1}$. As Diretrizes Curriculares Nacionais para os Cursos de Graduação em Fonoaudiologia ${ }^{2}$ indicam que o egresso/profissional em Fonoaudiologia dever ter "formação generalista, humanista, crítica e reflexiva", sendo sua atuação conduzida com rigor científico e intelectual. Quanto à formação do fonoaudiólogo, estas Diretrizes apontam que o 
profissional deve buscar autonomia pessoal e intelectual, aspectos necessários para empreender contínua formação profissional. As Diretrizes ainda reportam que a formação do Fonoaudiólogo tem por objetivo dotar o profissional dos conhecimentos requeridos para o exercício de competências e habilidades gerais, incluindo a capacidade de aprender continuamente.

As Instituições de Ensino Superior (IES) representam o ambiente propício para produzir conhecimentos que aproximem os serviços de saúde e as instâncias formadoras de profissionais de nível superior, voltados para a atenção integral à saúde ${ }^{3,4}$, além de criar mecanismos de aproveitamento de conhecimentos adquiridos pelo estudante, por meio de estudos e práticas independentes, presenciais e/ou à distância. Nesse sentido, os programas de iniciação científica vinculados aos programas de Graduação são considerados essenciais para o aprendizado inicial da pesquisa científica, bem como de sua relevância para o crescimento científico e profissional ${ }^{5}$. O amadurecimento necessário para o desenvolvimento da pesquisa científica ocorre, no entanto, a partir da inserção do profissional em Programas de Pós-Graduação (PPG), especialmente em Programas Stricto Sensu. A função dos programas de mestrado e doutorado é formar os quadros de cientistas e professores de nível superior para garantir ao País potencial de produção de conhecimento, de tecnologia e de aprendizagem compatível com as exigências da Ciência em âmbito internacional. Os programas precisam formar pessoas capazes, nas universidades e fora delas, de transformar o conhecimento científico mais recente e de boa qualidade em atuações profissionais significativas para a sociedade ${ }^{6}$. Assim, têm sido realizadas reflexões sobre a natureza da produção científica e a mobilização dos profissionais para obter melhor qualificação científica, sobretudo na formação de doutores?

Assim como ocorre com as demais ciências, os PPG em Fonoaudiologia têm um papel importante no contexto das IES e em relação à gestão de Ciência, tecnologia e ensino superior no País. Esta área de Fonoaudiologia conta atualmente com sete PPG - Nível Mestrado Acadêmico, sendo cinco em Fonoaudiologia/Distúrbios da Comunicação e dois em Ciências da Reabilitação. Conta ainda com cinco PPG - Nível Doutorado, sendo três em Fonoaudiologia/Distúrbios da Comunicação e dois em Ciências da Reabilitação ${ }^{8}$. Os PPG em Fonoaudiologia, juntamente com os PPG em Fisioterapia, Terapia Ocupacional e Educação Física, constituem a Área 21- Coordenação de Aperfeiçoamento de Pessoal em Ensino Superior (CAPES). Segundo o Documento dessa Área, de $2009^{\circ}$, o desenvolvimento científico da Área 21 cresceu bastante nos últimos anos, fato que pode ser observado no aumento significativo de Grupos de Pesquisa cadastrados no Conselho Nacional de Desenvolvimento Científico e Tecnológico (CNPq). Sendo uma área de característica eminentemente interdisciplinar, a Ciência Fonoaudiológica possui pontos de convergência com pelo menos quatro grandes áreas do conhecimento acadêmico: (1) Ciências Biológicas; (2) Ciências da Saúde; (3) Ciências Sociais e (4) Ciências Humanas. Historicamente, a Medicina, a Linguística, a Educação e a Psicologia ocuparam o papel de interlocutoras na formação da estrutura teórica e metodológica da Fonoaudiologia. Em certa medida, estas áreas de conhecimento ainda dialogam com a Fonoaudiologia. No entanto, ao longo do seu desenvolvimento, a Fonoaudiologia foi se desprendendo da dependência destas outras áreas de conhecimento, o que não significa dizer que se tornou autônoma, nem que não busque frequentemente aproximação com diferentes áreas ${ }^{10,11}$.

Considerando a característica interdisciplinar da Fonoaudiologia e a inserção de fonoaudiólogos em PPG de diferentes áreas correlatas, a formação fonoaudiológica tem sido alvo de investigação. Um estudo conduzido na cidade de São José dos Campos/SP ${ }^{12}$ indicou que, dos 104 profissionais que responderam a um questionário abrangendo várias questões de interesse, 60 profissionais participaram de PPG. No entanto, a maioria (56) desses profissionais participou de cursos de especialização (com maior concentração nas áreas de Motricidade Oral ou de Audiologia), sendo que somente quatro profissionais se vincularam a PPG Stricto Sensu, nível mestrado. Outro estudo teve como objetivo investigar as percepções do fonoaudiólogo recémformado quanto à sua formação, intenção profissional e busca por atualização de conhecimento. Participaram fonoaudiólogos graduados nos anos de 2005 e 2006, em cursos de formação no estado, os quais foram submetidos a um questionário constituído por dez perguntas fechadas. A especialização foi o curso mais pretendido $(70 \%)$, seguido do mestrado (61\%), da atualização (30\%) e do doutorado (26\%). Para justificar estes interesses, os autores destacam que no estado do Rio de Janeiro existe apenas um Curso de Pós-Graduação Stricto Sensu (mestrado profissionalizante) recomendado pela CAPES, oferecido por uma instituição privada, portanto, pago. Além disso, não há doutorado em Fonoaudiologia naquele estado ${ }^{13}$.

Já o estudo desenvolvido pelo Conselho Regional de Fonoaudiologia, da $2^{\text {a }}$ Região - São Paulo ${ }^{14}$, teve como objetivos atualizar os conhecimentos sobre a caracterização do perfil sóciodemográfico, a formação especializada e a inserção 
no mercado de trabalho dos profissionais inscritos no Conselho, com base nos 12.254 fonoaudiólogos inscritos, obtendo por sorteio aleatório uma amostra final de 1.675 respondentes. No que se refere à formação em PPG Stricto Sensu, $11,7 \%$ dos fonoaudiólogos (196 entrevistados da amostra) confirmaram ter realizado a pós-graduação. A maioria cursou somente o mestrado $(78,06 \%)$, seguido daqueles que cursaram o mestrado e o doutorado $(20,41 \%)$ e somente o doutorado (1,53\%). Dentre os que cursaram o mestrado, 153 (56,48\%) obtiveram algum tipo de financiamento e dentre os que cursaram doutorado, $43(37,21 \%)$ tiveram auxílio financeiro. As agências de fomento à pesquisa, indicadas pelos entrevistados, em ordem decrescente, foram basicamente: a CAPES, o CNPq e a Fundação de Amparo à pesquisa do Estado de São Paulo (FAPESP). A formação no mestrado ocorreu basicamente nas áreas de Linguagem $(22,11 \%)$, Audiologia (20\%), Voz (12,63\%), Motricidade Orofacial $(7,37 \%)$ e Saúde Coletiva (5,26\%). Quanto ao doutorado, tal formação ocorreu nas áreas de Audiologia (23,26\%), Linguagem (16,28\%), Voz (11,63\%), Motricidade Orofacial (6,98\%) e Saúde Coletiva (2,33\%). Quanto ao local de formação em pós-graduação, predominou tanto para o mestrado como para o doutorado, a capital do Estado de São Paulo. Um estudo que analisou a formação educacional do fonoaudiólogo brasileiro apontou para o fato de o Brasil ser responsável por $1 \%$ de toda publicação científica no mundo, evidenciando a necessidade de melhor distribuição de profissionais em território brasileiro ${ }^{15}$. Outro estudo, recentemente conduzido ${ }^{16}$, teve como objetivo analisar a formação dos doutores fonoaudiólogos brasileiros, observando-se que a maioria das teses foi defendida por mulheres, em instituições estaduais, e em programas inseridos nas Ciências da Vida, de acordo com a subdivisão proposta pelo CNPq. Quanto à temática desenvolvida na tese, um maior número correspondeu às áreas da Linguagem $e$ da Audição. Observou-se, ainda, um crescimento do número de teses no período estudado (1976 a 2008), segundo o ano, tendência observada também na escolha do Programa e nas áreas de Linguagem e Motricidade e Funções Orofaciais. Os autores atribuíram este crescimento ao aumento das teses defendidas em instituições públicas, particularmente, as estaduais.

Estudos que se preocupam com a formação de profissionais em PPG são de interesse de outras áreas do conhecimento, além da Fonoaudiologia. No caso da Medicina ${ }^{17}$, uma pesquisa realizada com o objetivo de analisar o perfil sociodemográfico, econômico-financeiro e técnico-científico dos egressos de um Curso de Medicina, verificou que a maioria havia terminado ou ainda estava cursando residência, enquanto a minoria tinha cursado o mestrado. Em relação à área da Fisioterapia ${ }^{18}$, um estudo que visou traçar o perfil destes profissionais pesquisadores quanto à sua formação, produção científica e bolsas obtidas por órgão de fomento, verificou grande ampliação (900\%) no número de doutores com graduação em Fisioterapia, na última década, em áreas tradicionais ou novos campos de atuação.

Observa-se, também, grande interesse pela busca de informações sobre a produção de conhecimento na área da Fonoaudiologia. Tal fato pode ser exemplificado por estudo prévio ${ }^{19} \mathrm{em}$ que se realizou análise da produção de conhecimento da área dos Distúrbios da Comunicação. Neste estudo, foram analisados os artigos publicados em quatro periódicos da área (Revista de Distúrbios da Comunicação; Revista da Sociedade Brasileira de Fonoaudiologia; Revista Fono Atual e Revista PróFono), no período de 2000 a 2005. Dos 724 artigos publicados, a temática predominante foi Linguagem Oral (282), de forma isolada ou combinada, seguida de Audiologia (232), Motricidade Oral (91) e Voz (62). Frente ao exposto, verifica-se uma preocupação das áreas de conhecimento e, em especial, da Fonoaudiologia, em conhecer como ocorre a inserção de graduados de Fonoaudiologia em PPG. Além disso, observa-se a necessidade de ampliar as investigações sobre a produção de conhecimento de profissionais fonoaudiólogos. Assim, esta pesquisa teve como objetivo caracterizar a inserção dos egressos de um curso de graduação em Fonoaudiologia de uma Universidade Pública Estadual em PPG Stricto Sensu no Brasil.

\section{MÉTODO}

Este é um estudo transversal, de natureza descritivo-analítica. As informações de interesse para esta pesquisa dizem respeito ao curso de Fonoaudiologia da Faculdade de Filosofia e Ciências da Universidade Estadual Paulista "Júlio de Mesquita Filho" - UNESP, Campus de Marília, no interior do Estado de São Paulo. O curso foi criado em 1990 e são matriculados anualmente 35 alunos. Ressalta-se que a UNESP, Campus de Marília, não oferece PPG em Fonoaudiologia. Foram utilizadas neste estudo: 1) as listas de graduados por turma, desde a primeira turma formada, abrangendo o período de 1993 a 2008; 2) o Curriculum Vitae (CV) do aluno egresso disponível na Plataforma LATTES do CNPQ (CV Lattes), no Item formação; 3) o CV Lattes do orientador; 4) site do Conselho Federal de Fonoaudiologia ${ }^{20}$ que apresenta as áreas de atuação da Fonoaudiologia para obtenção de 
título de especialista e 5) site da CAPES sobre o funcionamento e avaliação dos PPG ${ }^{8}$.

As listas de graduados foram examinadas e os seguintes critérios de inclusão do egresso no estudo foram considerados: a) ter concluído o curso de graduação em Fonoaudiologia no período de 1993-2008; b) ter ingressado em um PPG Stricto Sensu no Brasil e c) ter Curriculum Lattes preenchido e atualizado no momento da coleta de dados.

No que se refere ao CV Lattes do egresso, foram de interesse para o presente estudo as seguintes informações: a) modalidade do programa (mestrado e/ou doutorado); b) grande área do conhecimento; c) área do conhecimento; d) tema da dissertação/tese e respectiva área de especialidade do Conselho Federal de Fonoaudiologia, obtidas a partir do título e/ou do resumo da dissertação/tese; e) Instituição de Ensino Superior (IES) em que o PPG está vinculado; f) conceito atual do PPG, conforme site da $\mathrm{CAPES}^{8}, \mathrm{~g}$ ) se recebeu bolsa de estudo e, em caso positivo, qual a agência de fomento responsável e h) tempo após conclusão do curso.

O CV Lattes do orientador foi utilizado nos casos em que foram identificados alunos com situação de mestrado ou doutorado em andamento, com o CV Lattes desatualizado, a fim de complementar a informação de conclusão do curso.

O site do Conselho Federal de Fonoaudiologia ${ }^{20}$ subsidiou a classificação do tema da dissertação/ tese do egresso e a respectiva área de especialidade. Tal classificação foi realizada de forma independente por três juízes (fonoaudiólogos). Os juízes receberam uma planilha contendo os temas da dissertação e/ou da tese de cada um dos egressos, bem como uma cópia impressa das informações extraídas do site do Conselho Federal de Fonoaudiologia que dispõem sobre as áreas de especialidade da Fonoaudiologia. Após a leitura deste material, os juízes foram orientados a anotarem na planilha, em um campo destinado para isso, qual das áreas de especialidade mais se aproximava dos temas das dissertações e teses dos egressos. O preenchimento da planilha foi feito individualmente por cada juiz e de forma presencial. Na presença de dúvidas, os juízes foram orientados por um dos pesquisadores a selecionar área de especialidade que era o foco principal do estudo, ainda que mais de uma área pudesse ser identificada no título dos estudos. Após o preenchimento da planilha por cada um dos juízes, considerou-se para análise, a resposta cujo julgamento foi concordante para pelo menos dois juízes.

Informações sobre os PPG em que os egressos participantes deste estudo se inseriram, bem como a Área de Avaliação, Área Básica e Especificação destes PPG foram obtidas no site da CAPES ${ }^{8}$, instituição responsável pelo acompanhamento e avaliação dos cursos de PPG Stricto Sensu do Brasil.

No que se refere a aspectos éticos, em relação à coleta de dados extraída do CV Lattes, cabe ressaltar que cada pessoa preenche o seu próprio currículo, atestando a veracidade das informações prestadas e declara, por meio do "Termo de Adesão e Compromisso - Sistema de Currículos da Plataforma Lattes", a sua concordância em que as informações possam tornar-se públicas, resguardados alguns dos dados pessoais. Assim, as informações disponíveis foram consultadas e nenhum egresso ou orientador foi identificado individualmente. Em relação à obtenção da lista de formados e divulgação do nome da Instituição, foi obtida assinatura de Termo de Consentimento Livre e Esclarecido da Direção da Universidade. O projeto passou pelo Comitê de Ética em Pesquisa da mesma Universidade com processo de no 2869-2010.

Os dados extraídos do CV Lattes do egresso, do CV Lattes do orientador, dos documentos da CAPES, bem como os que resultaram das classificações dos juízes, foram registrados em uma planilha do programa Microsoft Office - Excel e submetidos à análise estatística descritiva e analítica. O Teste da Razão de Verossimilhança foi utilizado para comparar, em conjunto, a distribuição percentual do mestrado e do doutorado entre si. O nível de significância adotado foi de $p<0,05$.

\section{RESULTADOS}

O número total de formados no Curso de Fonoaudiologia no período em estudo foi de 537 , sendo que $89(16,57 \%)$ destes formados já haviam cursado ou estavam cursando Pós-Graduação na época da coleta.

A Tabela 1 mostra a distribuição de egressos em relação à grande área de conhecimento, em nível de mestrado e de doutorado. Ao serem comparados os valores do mestrado com os valores do doutorado para toda a Tabela, pode-se afirmar que a distribuição dos percentuais do mestrado é estatisticamente semelhante à distribuição dos percentuais do doutorado $(p=0,182)$.

No que se refere à área de conhecimento a que os egressos se vincularam, (Tabela 2), a distribuição dos percentuais do mestrado foi estatisticamente semelhante à distribuição dos percentuais do doutorado $(p=0,450)$.

A Tabela 3 mostra a distribuição de egressos do curso de Fonoaudiologia, que cursaram ou estavam cursando pós-graduação stricto sensu, de acordo com a área fonoaudiológica e o nível do curso. A distribuição dos percentuais do mestrado foi estatisticamente semelhante à distribuição dos percentuais do doutorado ( $p=0,880)$. 
Tabela 1 - Distribuição de egressos do curso de fonoaudiologia, que cursaram ou estavam cursando pós-graduação stricto sensu, de acordo com a grande área de conhecimento e o nível do curso ( $\mathrm{N}=89$ )

\begin{tabular}{lcccc}
\hline Grande área do & \multicolumn{2}{c}{ Mestrado } & $\mathbf{2}$ & Doutorado \\
\cline { 2 - 5 } conhecimento & $\mathbf{N}$ & $\%$ & 2 & $\%$ \\
\hline Ciências Biológicas & 2 & 2,27 & 11 & 33,33 \\
Ciências Humanas & 28 & 31,82 & 10 & 30,30 \\
Ciências da Saúde & 44 & 50,00 & 10 & 30,30 \\
Linguística, Letras e Artes & 12 & 13,64 & 0 & 0 \\
Engenharia & 1 & 1,14 & 0 & 0 \\
Multidisciplinar & 1 & 1,14 & $\mathbf{3 3}^{\text {**}}$ & $\mathbf{1 0 0}$ \\
\hline TOTAL & $\mathbf{8 8}^{*}$ & $\mathbf{1 0 0}$ &
\end{tabular}

* Dos 89 egressos, 1 não cursou o mestrado, mas o doutorado direto.

** Dos 89 egressos, 32 também cursaram/estavam cursando doutorado e 1 cursou doutorado direto.

Teste de Razão da Verossimilhança: $p=0,182$.

Tabela 2 - Distribuição de egressos do curso de fonoaudiologia, que cursaram ou estavam cursando pós-graduação stricto sensu, de acordo com a área de conhecimento e o nível do curso ( $\mathrm{N}=89)$

\begin{tabular}{lcccc}
\hline \multirow{2}{*}{ Área do conhecimento } & \multicolumn{2}{c}{ Mestrado } & $\mathbf{3}$ & $\%$ \\
\cline { 2 - 5 } & $\mathbf{N}$ & $\%$ & 1 & 3,03 \\
\hline Morfologia & 1 & 1,14 & 1 & 3,03 \\
Genética & 1 & 1,14 & 2 & 6,06 \\
\hline Medicina I & 8 & 9,09 & 2 & 6,06 \\
Medicina II & 3 & 3,41 & 2 & 6,06 \\
Medicina III & 4 & 4,55 & 0 & 0,00 \\
Odontologia & 1 & 1,14 & 1 & 3,03 \\
Enfermagem & 1 & 1,14 & 3 & 9,09 \\
Fonoaudiologia & 27 & 30,68 & 0 & 0,00 \\
\hline Filosofia & 2 & 2,27 & 11 & 33,33 \\
Educação & 25 & 28,41 & 0 & 0,00 \\
Psicologia & 1 & 1,14 & 10 & 30,30 \\
\hline Linguística & 12 & 13,64 & 0 & 0,00 \\
Engenharias & 1 & 1,14 & 0 & 0,00 \\
Interdisciplinar & 1 & 1,14 & $\mathbf{3 3}^{\text {**}}$ & $\mathbf{1 0 0}$ \\
\hline TOTAL & $\mathbf{8 8 ^ { * }}$ & $\mathbf{1 0 0}$ & & \\
\hline
\end{tabular}

* Dos 89 egressos, 1 não cursou o mestrado, mas o doutorado direto.

** Dos 89 egressos, 32 também cursaram/estavam cursando doutorado e 1 cursou doutorado direto.

Teste de Razão da Verossimilhança: $p=0,450$.

Tabela 3 - distribuição de egressos do curso de fonoaudiologia, que cursaram ou estavam cursando pós-graduação stricto sensu, de acordo com a área fonoaudiológica e o nível do curso ( $\mathrm{N}=89$ )

\begin{tabular}{|c|c|c|c|c|}
\hline \multirow{2}{*}{ Área Fonoaudiológica } & \multicolumn{2}{|c|}{ Mestrado } & \multicolumn{2}{|c|}{ Doutorado } \\
\hline & $\mathbf{N}$ & $\%$ & $\mathbf{N}$ & $\%$ \\
\hline Audiologia & 10 & 11,36 & 3 & 9,09 \\
\hline Linguagem & 49 & 55,68 & 17 & 51,52 \\
\hline Motricidade Oral & 12 & 13,64 & 5 & 15,15 \\
\hline Saúde Pública & 10 & 11,36 & 6 & 18,18 \\
\hline Voz & 7 & 7,95 & 2 & 6,06 \\
\hline TOTAL & $88^{*}$ & 100 & $33^{\star *}$ & 100 \\
\hline
\end{tabular}

* Dos 89 egressos, 1 não cursou o mestrado, mas o doutorado direto.

** Dos 89 egressos, 32 também cursaram/estavam cursando doutorado e 1 cursou doutorado direto.

Teste de Razão da Verossimilhança: $p=0,880$. 
Em relação às instituições de ensino superior em que os egressos se vincularam (Tabela 4), a distribuição dos percentuais do mestrado foi estatisticamente semelhante à distribuição dos percentuais do doutorado ( $p=0,341)$.

Dentre os conceitos dos programas em que os egressos se vincularam (Tabela 5), a distribuição dos percentuais do mestrado foi estatisticamente semelhante à distribuição dos percentuais do doutorado ( $p=0,379)$.

Em relação aos Órgãos de Fomento das bolsas recebidas pelos egressos, as informações são exibidas na Tabela 6. A distribuição dos percentuais do mestrado foi estatisticamente semeIhante à distribuição dos percentuais do doutorado $(p=0,875)$.

A Tabela 7 mostra a distribuição de egressos do curso de Fonoaudiologia, que concluíram a pósgraduação Stricto Sensu, de acordo com o tempo após conclusão do curso e o nível do curso. A distribuição dos percentuais do mestrado foi estatisticamente semelhante à distribuição dos percentuais do doutorado $(p=0,648)$.

Tabela 4 - Distribuição de egressos do curso de fonoaudiologia, que cursaram ou estavam cursando pós-graduação stricto sensu, de acordo com a instituição e o nível do curso ( $\mathrm{N}=89$ )

\begin{tabular}{lcccc}
\hline \multirow{2}{*}{ Instituições } & \multicolumn{2}{c}{ Mestrado } & $\mathbf{2}$ & Doutorado \\
\cline { 2 - 5 } & $\mathbf{N}$ & \% & $\mathbf{N}$ & $\%$ \\
\hline FEDERAIS & 11 & 12,50 & 2 & 6,06 \\
UNESP & 35 & 39,77 & 16 & 48,48 \\
UNICAMP & 10 & 11,36 & 6 & 18,18 \\
USP & 18 & 20,45 & 8 & 24,24 \\
PUC - SP & 11 & 12,50 & 1 & 3,03 \\
OUTRAS & 3 & 3,41 & 0 & 0,00 \\
\hline TOTAL & $\mathbf{8 8}$ & $\mathbf{1 0 0}$ & $\mathbf{3 3}$ & $\mathbf{1 0 0}$ \\
\hline
\end{tabular}

* Dos 89 egressos, 1 não cursou o mestrado, mas o doutorado direto.

** Dos 89 egressos, 32 também cursaram/estavam cursando doutorado e 1 cursou doutorado direto.

UNESP = Universidade Estadual Paulista

UNICAMP = Universidade Estadual de Campinas

USP = Universidade de São Paulo

PUC - SP = Pontifícia Universidade Católica de São Paulo

Teste de Razão da Verossimilhança: $p=0,341$.

Tabela 5 - distribuição de egressos do curso de fonoaudiologia, que cursaram ou estavam cursando pós-graduação stricto sensu, de acordo com o conceito da instituição e o nível do curso ( $\mathrm{N}=89$ )

\begin{tabular}{ccccc}
\hline \multirow{2}{*}{ Conceitos } & \multicolumn{2}{c}{ Mestrado } & D & Noutorado \\
\cline { 2 - 5 } & $\mathbf{N}$ & $\%$ & 1 & $\%$ \\
\hline 7 & 2 & 2,27 & 8 & 3,03 \\
6 & 8 & 9,09 & 7 & 24,24 \\
5 & 25 & 28,41 & 15 & 21,21 \\
4 & 46 & 52,27 & 1 & 45,45 \\
3 & 5 & 5,68 & 1 & 3,03 \\
2 & 2 & 2,27 & 3,03 \\
\hline TOTAL & $\mathbf{8 8}^{\boldsymbol{*}}$ & $\mathbf{1 0 0}$ & $\mathbf{3 3}^{\text {**}}$ & $\mathbf{1 0 0}$ \\
\hline
\end{tabular}

* Dos 89 egressos, 1 não cursou o mestrado, mas o doutorado direto.

** Dos 89 egressos, 32 também cursaram/estavam cursando doutorado e 1 cursou doutorado direto.

Teste de Razão da Verossimilhança: $p=0,379$. 
Tabela 6 - distribuição de egressos do curso de fonoaudiologia, que cursaram ou estavam cursando pós-graduação stricto sensu, de acordo com o órgão de fomento das bolsas recebidas pelo egresso e o nível do curso $(\mathrm{N}=89)$

\begin{tabular}{lcccc}
\hline \multirow{2}{*}{ Órgão de Fomento } & \multicolumn{2}{c}{ Mestrado } & \multicolumn{2}{c}{ Doutorado } \\
\cline { 2 - 5 } & $\mathbf{N}$ & $\%$ & $\mathbf{N}$ & $\%$ \\
\hline CAPES & 24 & 27,27 & 11 & 33,33 \\
CNPQ & 18 & 20,45 & 5 & 15,15 \\
FAPESP & 6 & 6,82 & 2 & 6,06 \\
Outros & 1 & 1,14 & 1 & 3,03 \\
Não consta & 39 & 44,32 & 14 & 42,42 \\
\hline TOTAL & $\mathbf{8 8}^{\boldsymbol{*}}$ & $\mathbf{1 0 0}$ & $\mathbf{3 3}^{\boldsymbol{*}}$ & $\mathbf{1 0 0}$ \\
\hline
\end{tabular}

Teste de Razão da Verossimilhança: $p=0,875$.

* Dos 89 egressos, 1 não cursou o mestrado, mas o doutorado direto.

** Dos 89 egressos, 32 também cursaram/estavam cursando doutorado e 1 cursou doutorado direto.

CAPES = Coordenação de Aperfeiçoamento de Pessoal em Ensino Superior

$\mathrm{CNPq}=$ Conselho Nacional de Desenvolvimento Científico e Tecnológico

FAPESP = Fundação de Amparo à pesquisa do Estado de São Paulo

Tabela 7 - distribuição de egressos do curso de fonoaudiologia que concluíram a pós-graduação stricto sensu, de acordo com o tempo após conclusão e o nível do curso $(\mathrm{N}=70)$

\begin{tabular}{|c|c|c|c|c|}
\hline \multirow{3}{*}{$\begin{array}{c}\text { Tempo após conclusão } \\
\text { (anos) }\end{array}$} & \multicolumn{4}{|c|}{ № de egressos titulados } \\
\hline & \multicolumn{2}{|c|}{ Mestrado } & \multicolumn{2}{|c|}{ Doutorado } \\
\hline & $\mathbf{N}$ & $\%$ & $\mathbf{N}$ & $\%$ \\
\hline$<1$ & 1 & 1,43 & 0 & 0 \\
\hline 1 & 7 & 10,00 & 1 & 10,00 \\
\hline 2 & 10 & 14,29 & 2 & 20,00 \\
\hline 3 & 14 & 20,00 & 1 & 10,00 \\
\hline 4 & 5 & 7,14 & 3 & 30,00 \\
\hline 5 & 6 & 8,57 & 1 & 10,00 \\
\hline 6 & 8 & 11,43 & 1 & 10,00 \\
\hline 7 & 5 & 7,14 & 0 & 0,00 \\
\hline 8 & 4 & 5,71 & 0 & 0,00 \\
\hline 9 & 1 & 1,43 & 1 & 10,00 \\
\hline 10 & 3 & 4,29 & 0 & 0,00 \\
\hline 11 & 4 & 5,71 & 0 & 0,00 \\
\hline 12 & 1 & 1,43 & 0 & 0,00 \\
\hline 13 & 1 & 1,43 & 0 & 0,00 \\
\hline TAL & 70 & 100 & 10 & 100 \\
\hline
\end{tabular}

Teste de Razão da Verossimilhança: $p=0,648$.

\section{DISCUSSÃO}

Os resultados obtidos neste estudo, no que se refere à realização de pós-graduação Stricto Sensu, nível mestrado e doutorado, por profissionais fonoaudiólogos $(16,57 \%)$, superaram aqueles apresentados pelo Conselho Regional de Fonoaudiologia, da $2^{\mathrm{a}}$ Região - SP $(11,7 \%)$, Estado em que esta pesquisa também foi realizada. No presente trabalho, os dados analisados foram provenientes de egressos que concluíram o curso a partir de 1994 e, portanto, relativamente recentes, diferentemente do estudo apresentado pelo Conselho Regional de Fonoaudiologia, da $2^{\text {a }}$ Região - SP ${ }^{14}$ em que a metodologia utilizada 
englobou uma amostra de 196 entrevistados, derivada de um sorteio aleatório de um total de 12.254 profissionais fonoaudiólogos inscritos no Conselho. Esta metodologia possivelmente contou com a inclusão de profissionais com tempo de conclusão de curso superior ao encontrado neste trabalho, em que a realidade de mercado e de acesso a cursos de $P G$ em Fonoaudiologia ou demais ciências possivelmente era mais restrita. Esta pesquisa pode ter tido resultados superiores devido ao maior acesso de egressos a PPG em Fonoaudiologia e áreas afins, recentemente implantados no Estado de São Paulo. Segundo o Documento de Área da CAPES $^{9}$, o desenvolvimento científico da Área 21, que inclui a área da Fonoaudiologia, cresceu muito nos últimos anos, o que pode ser observado pelo no aumento expressivo de Grupos de Pesquisa cadastrados no $\mathrm{CNPq}$, além da qualidade da produção científica. Um estudo recente ${ }^{16}$, que analisou a formação de doutores fonoaudiólogos brasileiros no período de 1976 a 2008, constatou que houve um crescimento significativo dos mesmos no país. Os autores concluem que este crescimento possibilita maior inserção do fonoaudiólogo em atividades de pesquisa e produção científica qualificada.

A frequência de realização de mestrado e doutorado, além disso, pode ter sido superior no presente estudo devido ao aumento do interesse de egressos pelo ensino e pela pesquisa, conforme já apontado em estudo prévio envolvendo área afim $^{16}$. Tal interesse pode ser resultante da característica inerente de cursos de graduação de universidades públicas, que motivam seus alunos a amadurecerem os conhecimentos previamente adquiridos na iniciação científica, a partir do ingresso em PPG (mestrado e doutorado). Conforme apontado na literatura ${ }^{6}$, os PPG Stricto Sensu objetivam formar pessoas que sejam capazes, nas universidades e fora delas, de transformar o conhecimento científico mais recente e de boa qualidade em atuações profissionais significativas para a sociedade. Assim, a busca de novos conhecimentos, somada à expectativa de tornálos mais acessíveis, bem como facilitar o seu uso pela sociedade 6 , pode justificar os maiores resultados do presente trabalho. Ressalta-se, ainda, os resultados de um estudo recente ${ }^{16}$ que destacou a mobilização de fonoaudiólogos em busca de melhor capacitação científica.

A frequência de realização de mestrado e doutorado observada no presente estudo difere daquelas encontradas para profissionais fonoaudiólogos de uma cidade do interior do Estado São Paulo ${ }^{12}$. No entanto, concordaram com aqueles apresentados em nível regional ${ }^{14}$ no que diz respeito à modalidade de programas cursados (mestrado e/ou doutorado), uma vez que a maioria dos egressos também cursou somente o mestrado, ( $N=56 ; 62,92 \%)$, seguido daqueles que cursaram mestrado e doutorado $(\mathrm{N}=32,35,95 \%)$ e somente doutorado $(\mathrm{N}=1$; $1,12 \%)$. Tal fato pode ser explicado pela possível oportunidade de inserção no mercado de trabalho após a conclusão do mestrado, além do número reduzido de PPG, nível de doutorado, na área da Fonoaudiologia, no país.

A maioria dos egressos pesquisados, em nível de mestrado, vinculou-se a programas em Ciências da Saúde e em Ciências Humanas, seguidos de Linguística, Letras e Artes. Em nível de doutorado, a maioria se vinculou a programas em Ciências Humanas e em Linguistica, Letras e Artes, seguido de Ciências da Saúde. Considerando-se a característica interdisciplinar da Fonoaudiologia, a inserção de egressos deste estudo em PPG, tanto na área da Fonoaudiologia quanto em áreas afins, aponta para essa característica que, por sua vez, foi discutida em estudos anteriores ${ }^{11,14} \mathrm{~A}$ interdisciplinaridade na formação do fonoaudiólogo também foi destacada em estudo recente ${ }^{16}$.

A diversificação no olhar dos processos saudáveis e desviantes por pesquisadores das áreas das Ciências Biológicas, da Saúde e das Ciências Humanas vem alterando paradigmas da Ciência Fonoaudiológica. Historicamente, a Fonoaudiologia originou-se das Ciências da Saúde e das Ciências Humanas, sendo seu principal objeto de atuação a reabilitação para "sanar" ou "amenizar" os diferentes distúrbios da comunicação que acometem o ser humano ao longo de sua vida. Esta prática, no entanto, foi sendo revista e gradativamente deu lugar a investigações científicas que procuravam responder questões sobre os diferentes distúrbios fonoaudiológicos. Embora ao longo do seu desenvolvimento a Fonoaudiologia tenha se desprendido da dependência de outras áreas de conhecimento, a aproximação com diferentes áreas é uma prática frequente ${ }^{11}$.

Por exemplo, com o objetivo geral de compreender melhor o contexto da Fonoaudiologia no Brasil e, particularmente, sua relação com a Educação, um estudo realizado apontou que historicamente a Fonoaudiologia, desde seu início, esteve bastante ligada à Educação. Porém, distanciou-se dela quando da formação dos cursos de nível superior e, em razão das necessidades e possibilidades do mercado de trabalho, de interesses políticos, econômicos e sociais mais abrangentes, a relação com a Educação tem sido reconquistada, bem como a prática fonoaudiológica tem acompanhado as tendências educacionais e feito uso das teorias da educação e da aprendizagem ${ }^{10}$.

Reflexões sobre a natureza multidisciplinar da Fonoaudiologia são apresentadas em outras 
investigações ${ }^{10,11}$ Os achados do presente estudo corroboram a literatura, uma vez que os egressos estudados se inseriram em PPG em diferentes áreas de conhecimento (Tabelas 1 e 2), resultando em produção científica diversificada. Ainda se assemelham aos achados de um estudo prévio ${ }^{12}$, que teve como objetivo traçar o perfil da formação dos profissionais fonoaudiólogos e que foi motivado pela natureza da Ciência Fonoaudiológica que apresenta característica eminentemente interdisciplinar. A natureza interdisciplinar da Fonoaudiologia ainda foi constatada em estudo recente ${ }^{16}$ que encontrou números similares de doutores em programas relacionados tanto às Ciências da Vida quanto em Ciências Humanas e Sociais Aplicadas, conforme divisão de área proposta pelo CNPq. Nesta pesquisa, observou-se que, em nível de doutorado, os egressos procuraram mais programas nas Grandes Áreas Ciências Humanas/ Linguística, Letras e Artes do que Ciências da Saúde/Biológicas, conforme divisão proposta pela CAPES, sugerindo que esses egressos permaneceram em programas oferecidos pela própria IES, conforme apresentado na Tabela 4.

Em relação aos temas das dissertações de mestrado e teses de doutorado, os resultados do presente estudo indicaram que a área da linguagem prevaleceu, tanto em relação ao tema das dissertações de mestrado ( $\mathrm{N}=49 ; 55,68 \%$ ), quanto ao tema das teses do doutorado ( $\mathrm{N}=17 ; 51,52 \%)$ (Tabela 3 ), se concordando com os achados apresentados em estudos prévios ${ }^{16,19}$. Um destes estudos, que analisou a produção de conhecimento da área dos Distúrbios da Comunicação, apontou a linguagem oral (de forma isolada ou combinada) como a temática predominante da produção científica do pesquisador fonoaudiólogo em quatro periódicos do Brasil $^{19}$. Outro estudo que analisou a formação dos doutores fonoaudiólogos brasileiros ${ }^{16}$, no período de 1976 a 2008, encontrou a linguagem como a temática que prevaleceu nas teses.

Ainda, sobre o tema das dissertações de mestrado e das teses de doutorado, os resultados do presente estudo concordam parcialmente com os apresentados na literatura ${ }^{14}$, que apontou a área da linguagem como a mais investigada nos cursos de mestrado e a área da audiologia como a mais estudada em cursos de doutorado. Neste trabalho, observou-se que a linguagem se sobrepôs, tanto no mestrado quanto no doutorado, o que pode ser um tema mais focalizado em PPG das áreas da Educação e da Linguística. Ressalta-se, ainda, que a produção científica dos egressos evidencia o caráter multiprofissional e interdisciplinar dos PPG cursados. Tal produção vai ao encontro do panorama atual da Área 21 - CAPES que expressa uma forte expectativa de crescimento quantitativo e qualitativo dessa Área, bem como aponta seu caráter multiprofissional e interdisciplinar, com produção científica variando desde as áreas biológicas e médicas, até as áreas das humanidades.

Conforme exposto na Tabela 4, a tendência dos egressos em buscar PPG na própria Instituição em que se graduou talvez se deva à maior possibilidade de dar continuidade a projetos de pesquisas de iniciação cientifica com os próprios orientadores do curso de Graduação, pois houve grande procura dos egressos da UNESP por cursos de PPG nas áreas da Educação e da Linguística na mesma IES de origem. Ressalta-se, ainda, que a USP foi observada como a segunda IES mais procurada pelos egressos para se vincular a PPG, talvez pelo número de programas oferecidos na Área 21-Capes. Além disso, a procura por PPG na mesma IES pode ter ocorrido em função da facilidade e/ou comodidade do egresso em se manter geograficamente onde já possui sua vida acadêmica, profissional e pessoal estruturada, favorecendo seu percurso acadêmico, evitando, assim, mudanças drásticas que são inevitáveis quando se busca a continuidade de estudos em cidade mais distante ou, até mesmo, em outro estado.

Dentre os conceitos dos programas em que os egressos se vincularam, o conceito 4 predominou, tanto em nível de mestrado quanto em nível de doutorado, seguido do conceito 5 para o nível de mestrado e os conceitos 5 e 6 para o doutorado (Tabela 5). Tais resultados podem demonstrar preferência dos egressos para cursos que são apontados como de excelência pela CAPES ${ }^{8}$, assim como podem ser resultantes da preferência dos egressos em permanecerem na mesma IES da graduação para seus estudos de pós-graduação que, por sua vez, podem possuir conceitos mais elevados.

Quanto à bolsa de estudos recebida pelos egressos, observou-se, para os que apresentaram essa informação em seu CV Lattes que, dentre os que cursaram o mestrado, $49(55,68 \% \%)$ obtiveram algum tipo de financiamento e dentre os que cursaram doutorado, 19 (57,57\%) tiveram auxílio financeiro (Tabela 6). Estes resultados se assemelham aos apresentados em estudo anterior ${ }^{14}$, bem como apontam para o apoio das agências de fomento para o crescimento científico do país, principalmente em programas bem conceituados, e permitem que os pós-graduandos se envolvam integralmente em atividades científicas e de preparo à docência.

Dentre os 70 egressos que concluíram Pósgraduação até o momento da coleta de dados, a maioria concluiu o mestrado nos últimos quatro 
anos, fato também observado para o doutorado (Tabela 7). Estes achados indicam que nos últimos anos um maior número de egressos tem buscado o aprofundamento de seus conhecimentos científicos, o que pode ser justificado tanto pelas oportunidades de mercado de trabalho na área acadêmica, como também pelo maior apoio financeiro das agências de fomento para a participação em PPG.

\section{CONCLUSÃO}

Houve inserção dos egressos da UNESP, Campus de Marília, em PPG Stricto Sensu com frequência relativamente elevada.

Entre os PPG que os egressos estão cursando ou cursaram em nível de mestrado, destacaram-se aqueles ligados à Grande Área da
Saúde (Fonoaudiologia), das Ciências Humanas (Educação) e da Linguística, Letras e Artes (Linguística). Em relação ao doutorado, destacaram-se aqueles ligados às Ciências Humanas (Educação), Linguística, Letras e Artes (Linguística) e Ciências da Saúde (Fonoaudiologia). Os resultados ainda mostraram a característica eminentemente interdisciplinar da Ciência Fonoaudiológica, o predomínio de temática voltada para a linguagem, do conceito 4 para ambos os níveis de PPG e da ausência de informações sobre o fomento, apesar de ser evidente que mais da metade dos egressos de ambos os níveis de PPG o possuíam.

De forma geral, os resultados obtidos neste estudo podem contribuir para o maior entendimento da busca de conhecimentos do fonoaudiólogo em PPG.

\begin{abstract}
Purpose: to characterize the insertion of undergraduate students from a Speech and Language Therapy Course at São Paulo State University - UNESP in Graduate Programs. Method: we used a list and the Curriculum Vitae of these students and their respective mentors. Results: of the 537 graduates, $16.57 \%$ attended/were attending Graduate Programs, and of these, $98.88 \%$ were working at a Master Program and $37.08 \%$ at a Doctoral. Regarding the broad area of knowledge, $50 \%$ of master's students were enrolled in Health Science programs, $31.80 \%$ in Humanities and $13.64 \%$ in Linguistics. For doctoral level, 33, 33\% were enrolled in Humanities and $30.30 \%$ in Health Sciences as well as in Linguistics. Regarding the knowledge specific area, $30.68 \%$ of Master's students were enrolled in Speech Pathology programs, $28.41 \%$ in Education, $13.64 \%$ in Linguistics and $9.09 \%$ in Medicine I. For doctorate level, 33.33\% were enrolled in Education programs, $30.30 \%$ in Linguistics and $9.09 \%$ in Speech Pathology. Additionally, 55.68\% dissertations and $51.52 \%$ thesis were focused on the language area. UNESP was the university that most attended: $39.77 \%$ and $48.48 \%$ students in master and doctoral programs, respectively. Among the overall students, $52.27 \%$ from master and $45.45 \%$ from doctoral levels were linked to programs with concept grade 4 . When the information was available, all received scholarship. Test of Reason of Probabilities did not show significance differences between master and doctoral levels. Conclusion: findings were higher than previously reported for the same state, showing the highly interdisciplinary nature of the field of Communication Disorders, and the predominance of "Language" as the studied theme.
\end{abstract}

KEYWORDS: Speech; Education; Human Resources Formation

\section{REFERÊNCIAS}

1. Conselho Federal de Fonoaudiologia. Áreas de competência do fonoaudiólogo no Brasil. [homepage na internet]. Brasília: Conselho Federal de Fonoaudiologia; 2007. [acesso 3 mar. 2010]. Disponível em: http://www.fonoaudiologia.org. brdiscovirtual/pubdownload/epacfbr.pdf

2. Brasil, Conselho Nacional de Educação. Resolução CNE/CES 5, de 19 de fevereiro de 2002.
Institui diretrizes curriculares nacionais do curso de graduação em fonoaudiologia. Diário Oficial da União, Brasília, 4 mar. 2002. Seção 1. p.12. [acesso 3 mar. 2010]. Disponível em: http://portal.mec.gov. br/cne/arquivos/pdf/CES052002.pdf

3. Haddad AE, Morita MC, Pierantoni CR, Brenelli SL, Passarella T, Campos FE Formação de profissionais de saúde no Brasil: uma análise no período de 1991 a 2008. Rev Saúde Pública [periódico na Internet]. 2010;44(3):383-93. Disponível em: http://www. 
scielo.br/scielo.php?script=sci_arttext\&pid=S0034$89102010000300001 \&$ lng=pt. Epub 21-Maio-2010. doi: 10.1590/S0034-89102010005000015.

4. Araújo D, Miranda MCG, Brasil SL Formação de profissionais de saúde na perspectiva da integralidade. Revista Baiana de Saúde Pública. 2007;31(1):20-31.

5. Erdmann AL, Leite JL, Nascimento KC, Lanzoni GMM. Vislumbrando o significado da iniciação científica a partir do graduando de enfermagem. Esc Anna Nery Rev Enferm. 2010;14(1):26-32.

6. Botomé SP, Kubo OM. Responsabilidade social dos programas de pós-graduação e formação de novos cientistas e professores de nível superior. Interação em Psicologia. 2002;6(1):81-110.

7. Declercq E, Caldwell K, Hobbs SH, Guyer B. The changing pattern of doctoral education in public health from 1985 to 2006 and the challenge of doctoral training for practice and leadership. Am J Public Health. 2008;98(9):1565-9.

8. Brasil, Ministério da Educação, Coordenação de Aperfeiçoamento de Pessoal de Nível Superior. Relação de cursos recomendados e reconhecidos. [homepage na internet]. Brasília: Coordenação de Aperfeiçoamento de Pessoal de Nível Superior; 2007. [acesso 3 mar. 2010]. Disponível em: http:// conteudoweb.capes.gov.br/conteudoweb/ProjetoR elacaoCursosServlet?acao=pesquisarles\&codigo $A$ rea $=40700003 \&$ descricao Area $=\mathrm{Cl} \% \mathrm{CANCIAS}+\mathrm{DA}$ +SA\%DADE+\&descricaoAreaConhecimento=FON OAUDIOLOGIA\&descricaoAreaAvaliacao=EDUCA $\% \mathrm{C} 7 \% \mathrm{C} 3 \mathrm{O}+\mathrm{F} \% \mathrm{CDSICA}$

9. Brasil, Ministério da Educação, Coordenação de Aperfeiçoamento de Pessoal de Nível Superior. Documento de área 2009. [homepage na internet]. Brasília: Coordenação de Aperfeiçoamento de Pessoal de Nível Superior; 2009. [Acesso 3 mar. 2010]. Disponível em: http://www.capes.gov. br/images/stories/download/avaliacao/EDU_ FIS15out2009.pdf

10. Bacha SMC, Osório AMN. Fonoaudiologia \& educação: uma revisão da prática histórica. Rev CEFAC. 2004;6(2):215-21.

http://dx.doi.org/10.1590/S1516-18462011005000110

RECEBIDO EM: 11/08/2010

ACEITO EM: 04/11/2010

Endereço para correspondência:

Viviane Cristina de Castro Marino

Av. Higino Muzzi Filho, 737

Marília - SP

CEP: $17525-900$

E-mail: vivianemarino2@yahoo.com.br
11. Freire RM, Passos MC. Uma análise da produção de conhecimento no interior do PPG em fonoaudiologia: de sua fundação até o novo milênio. Disturb Comun. 2005; 17(1):37-43.

12. Stefaneli FR, Monteiro KDGM, Spinelli RL. Perfil do fonoaudiólogo na cidade de São José dos Campos. Rev CEFAC. 2004;6(1):101-5.

13. Silva DGM, Sampaio TMM, Bianchini EMG. Percepções do fonoaudiólogo recém-formado quanto à sua formação, intenção profissional e atualização de conhecimentos. Rev Soc Bras Fonoaudiol. 2010;15(1):47-53.

14. Conselho Regional de Fonoaudiologia $2^{\mathrm{a}}$ Região. Perfil de formação especializada e inserção no mercado de trabalho do fonoaudiólogo no Estado de São Paulo. [homepage na internet]. São Paulo: Conselho Regional de Fonoaudiologia $2^{\mathrm{a}}$ Região; 2009. [acesso 3 mar. 2010]. Disponível em: http://www.fonosp.org.br/wordpress/wp-content/ uploads/2010/01/relatorio-final-cealag_01-12.pdf

15. Behlau M, Gasparini G. Education of speechlanguage pathologists and audiologists in Brazil. Folia Phoniatr Logop. 2006;58(1):14-22.

16. Ferreira LP, Russo ICP, Adami F. Fonoaudiólogos doutores no Brasil: perfil da formação no período de 1976 a 2008. Pró-Fono R Atual Cient. 2010;22(2):89-94.

17. Caovilla F, Leitzke L, Menezes HS, Martinez PF. Perfil do médico egresso do Curso de Medicina da Universidade Luterana do Brasil (Ulbra). Rev AMRIGS. 2008;52(2):103-9.

18. Coury HJCG, Vilella I. Perfil do pesquisador fisioterapeuta brasileiro. Rev Bras Fisioter. 2009;13(4):356-63.

19. Berberian AP, Ferreira LP, Corteletti LCBJ, Azevedo JBM, Marques JM. A produção do conhecimento em distúrbios da comunicação: análise de periódicos (2000-2005). Rev Soc Bras Fonoaudiol. 2009;14(2):153-9.

20. Conselho Federal de Fonoaudiologia. Especialização: título de especialista por área. [homepage na internet]. Brasília: Conselho Federal de Fonoaudiologia; 2008. [Acesso 3 mar. 2010]. Disponível em: http://www.fonoaudiologia.org.br/ subpag.jsp?tpPag=TE. 